The induction of abortion must be considered in those cases which come under the third and fourth divisions of $\mathrm{my}$ classifieation.

The responsibility of such an operation should be a divided one, and the patient should have the benefit of it before too late, not waiting too lcng under the hope that vomiting may suddenly subside, as it sometimes does. Strict antiseptic precautions and anaesthesia are absolntely necessary to ensure a favourable termination. Lloyd Roberts says "in hyperemesis gravidarum he had never regretted the performance of induction." The following is an illustrative case :

\section{Case vi.}

I. J., aged 26 , belonging to the upper classes, prepossessing in appearance, strong and athletic, and one who prided herself upon being free from women's ordinary ailments, became pregnant for the second time, had persistent vomiting accompanied by great emaciation, which came on in the tenth week ; rectal alimentation was not tolerated, so abortion was induced. Recovery, though protracted, was satisfactory and complete.

This was a typical case for operative procedure. Patient could not have survived if the operation had been longer delayed.

The next case I have to record is one of unusual capidity.

CASE VIr.

M. $R$. aged 4r, cotton operative, was admitted in August last to the Blackburn and East Lancashire Infirmary. Her medical attendant thought there might be intestinal obstruction, but stated she was eight to nine weeks advanced in pregnancy. The vomiting and collapse were very severe, and all the symptoms pointing to pernicious vomiting of pregnancy, abortion was induced. She died from exhaustion pure and simple, verified by post-mortem examination. This was a very rapidly fatal and unfortunate case.

\section{Conclustons.}

From the foregoing and many other cases which have come under my direct observation, I conclude :

First, that there is simple nausea with or without actual emesis of physiological and reflex origin, a symptom only due to hyperaemia, the developing uterus, vessels, and nerves in a confined cavity.

Secondly, that malposition of the uterus, if the cause of so many troubles in orcinary conditions of health, must be a graver trouble in the pregnant woman, and thus increases the vomiting of pregnancy and consequent malnutrition and emaciation

Thirdly, that in the absence of uterine troubles and organic disease, hysteria plays an important rôle, and usually defies all therapentical remedies. I emphasize here that if operation should be deemed necessary, it should be carried out under thoroughly antiseptic conditions and anaesthesia.

Fourthly, that it is probable in pregnancy, with its increased arterial tension, and where lung and cardiac complications exist, gastric irritation may be set up and continued in consequence of the special toxaemia which at present is only suspected, but which in further researches $I$ feel convinced will be scientifically proved.

In conclusion, the better attention to health and the greater inclination to athletic exercises and hygienic surroundings of our present-day girls may naturally come to counteract the artificial existence which has for so many years existed in our child-bearing population.

assheton-Smith Marine Biological Station.-We have received from Professor Phillip J. White a note upon the interest taken by the late Mr. Assheton-Smith in the zoological department of the University College of North Wales, Bangor. Mr. Assheton-Smith liked nothing better, Professor White states, than to go the rounds of his park at Vaynol with a guest and to point out and discuss the characters and habits of the animals which he had gathered together from various quarters of the globe. Not only did he afford to men of science an opportunity of studying animals under favourable circumstances, but he was able to place material at the disposal of the laboratory and the museum when these animals had paid the last debt of Nature. Owing to his interest in the zoological department of the University College, the professor and students were able to carry out not a few researches in comparative anatomy. His zoological donations and his gift to the College of a site on the Menai Straits for a biological station for the study of marine life bear eloquent testimony to his desire to advance science, and Professor White expresses the hope that a fund may be raised to erect on this fine site a building which will be a suitable tribute to Mr. Assheton-Smith's memory.

\section{SUGGESTION FOR A CUBIC CENTIMETRE MEASURE FOR PATIENT'S USE.}

By J. THEODORE CASH, M.D.EdiN., F.R.S.,

Regius Professor of Materia Medica, University of Aberdeen.

IN my address to the Aberdeen Medico-Chirurgical Society on November 3 rd I dealt with certain points relating to the dosage of remedies, and in conclusion accentuated the great importance of a speedy change from the present chaotic

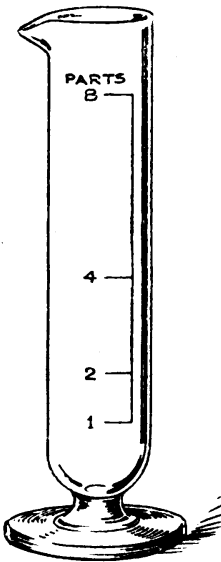
system of weights and measures to the decimal standard.

When we seriously apply ourselves to this change, the question of measurement of the prescribed dose for the recipient must be carefully considered and satisfactorily provided for. The so-called domestic measures-spoons, wineglasses, etc. - are so unsatisfactory, owing to the great variations in capacity which they possess individually, that their use should be entirely abandoned.

I suggested the employment of a cylindrical-footed measure-glass of eprouvette shape, which should bear only four graduation marks. The cylinder is $20 \mathrm{~cm}$. in height and $2 \mathrm{~cm}$. in diameter; it is provided with a small lip. The numbers corresponding to these marks do not represent the capacity in cubic centimetres. This would inevitably cause confusion amongst those uninstructed in the system.

But taking $2.5 \mathrm{c.cm}$. as a convenient unit for the purpose, this might correspond with the lowermost mark "1." The second mark " 2 " would represent $5 \mathrm{c.cm}$. The third " 4 " $(2.5 \times 4)$ 10c.cm.; the fourth (and uppermost) " 8 " $(2.5 \times 8)$ 20 c.cm.

Such figures would have the following rough correspondence with the domestic measures, provided that these were accurate :

\begin{tabular}{r|r|r|l}
\hline Parts. & Minims. & C.cm. & \multicolumn{1}{|c}{ Domestic Measure. } \\
\hline 8 & 338 & 20 & A large tablespoonful. 53 teaspoonfuls. \\
4 & 169 & Io & A large dessertspoonful. Nearly 3 teaspoonfuls. \\
2 & 84.5 & 5 & A large teaspoonful. \\
I & 42.25 & 2.5 & A small teaspoonful. \\
\hline
\end{tabular}

It would be a simple matter for the prescriber using the decimal system to find a convenient dose with the choice which such a scale affords, whilst the direction he might give, to take 2 parts, 8 parts, etc., of the remedy at the stated time intervals could scarcely admit of error. Such a system certainly involves the general employment of a measure, but as the cost of this would probably not exceed $3 \mathrm{~d}$. or $4 \mathrm{~d}$., I can see no reason why even the poorest patient should not possess it.

I venture to think that such a very simple method might help to bridge over a distinct difficulty in the adoption of the decimal system by British practitioners, and that it would favour a more exact medication, which would be in the interest of the patient under treatment, whilst it would increase the exactitude of therapeutical observation.

\section{MEMORANDA: \\ MEDICAL, SURGICAL, OBSTETRICAL, THERA- pedtical, Pathological, Etc.}

\section{ABSENCE OF UTERUS AND VAGINA.}

A SINGLE woman, aged 2I, came to the out-patient department at St. Thomas's Hospital on September 14th, r904, stating that she had never menstruated, and wishing to know the reason of this, and whether the periods were likely to appear. She had suffered no pain and felt well, except for occasional faintness and lassitude, due no doubt to a slight degree of anaemia. On abdominal examination nothing abnormal could be made out. A bimanual examination was then made 